\title{
COMPUTATIONAL AND EXPERIMENTAL INVESTIGATIONS OF CARBON-CERAMIC COMPOSITE MATERIALS THERMOCHEMICAL RESISTANCE IN COMBUSTION PRODUCTS OF LIQUID ROCKET ENGINE
}

\author{
V. V. Mironov, N. N. Volkov, L. I. Volkova, \\ V.I. Kondratenko, V. A. Popov, and S. M. Tsatsuev
}

\begin{abstract}
Computational and experimental investigations of thermochemical resistance of carbon-ceramic composites in the combustion products of liquid rocket engine (LRE) are presented. The tests with model extensions made of the composite material (CM) were performed. The test time was about $200 \mathrm{~s}$. The maximal temperature of the material fire surface was $1600 \mathrm{~K}$. Physical and numerical model of silicon carbide destruction was developed.
\end{abstract}

\section{INTRODUCTION}

Nonmetallic CMs possess density which is a factor of 4 to 5 less than that of conventional thermoresistant metals and alloys. They have already been successfully used in LRE (Fig. 1). For example, engine 11D58M with extension of radiant cooling made of carbon composite material has a lot of successful flights since 2003 as a part of Zenit 3SL.

Carbon-based CMs are attractive for their low density and high strength which increases with temperature. Also, the use of a protective covering allows increasing considerably their resistance to oxidizing environment.

\section{PHYSICOCHEMICAL DESTRUCTION MODEL}

Refractory carbides and metallic oxides are considered to be utilized in coverings protecting base carbon materials at temperatures near 1900-2000 K. Relatively stable protection in this temperature range can be provided by silicon carbide.

This is an Open Access article distributed under the terms of the Creative Commons Attribution-Noncommercial License 3.0, which permits unrestricted use, distribution, and reproduction in any noncommercial medium, provided the original work is properly cited. 


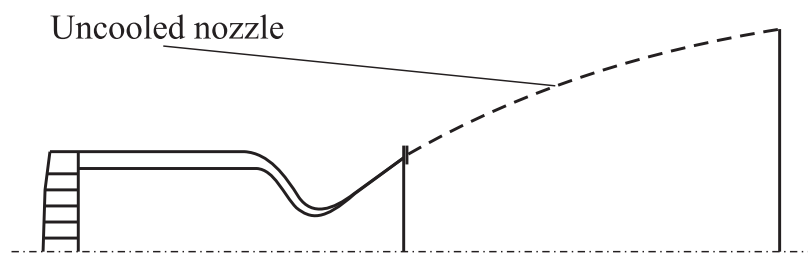

(a)

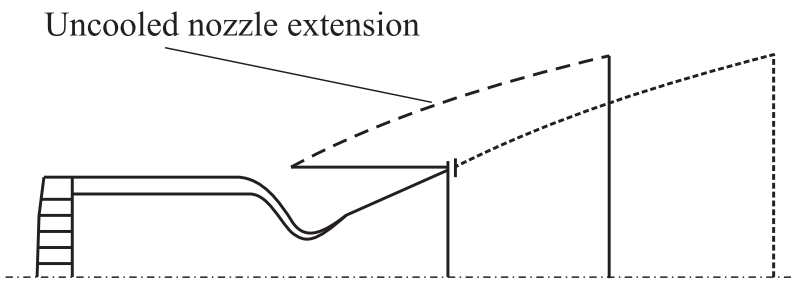

(b)

Figure 1 Possible CM applications in LRE

Silicon carbide contained in the protective material reacts with combustion products like $\mathrm{H}_{2} \mathrm{O}, \mathrm{CO}_{2}, \mathrm{O}_{2}$, and $\mathrm{O}$ with possible formation of a $\mathrm{SiO}_{2}$ film.

The most thermodynamically realistic reactions are listed below:

$$
\begin{aligned}
& \begin{array}{c}
\text { solid } \\
\mathrm{SiC}
\end{array}+2 \mathrm{O}_{2}=\begin{array}{c}
\text { solid, liquid } \\
\mathrm{SiO}_{2}
\end{array}+\begin{array}{c}
\text { gas } \\
\mathrm{CO}_{2}
\end{array} \\
& \mathrm{SiC}+3 \mathrm{CO}_{2}=\mathrm{SiO}_{2}+4 \mathrm{CO} \\
& \mathrm{SiC}+3 \mathrm{H}_{2} \mathrm{O}=\mathrm{SiO}_{2}+\mathrm{CO}+3 \mathrm{H}_{2}
\end{aligned}
$$

The $\mathrm{SiO}_{2}$ film plays a role of diffusion barrier for both oxidant components in the gas flow (interaction takes place on the $\mathrm{SiO}_{2}-\mathrm{SiC}$ interface) and for reaction products flow-out (Fig. 2). The film thickness is determined not only by its growth rate but also by the flow near the surface if temperatures are high enough to melt $\mathrm{SiO}_{2}$, so that this melt could be removed by frictional forces.

If the material surface layers contain carbon particles, the $\mathrm{SiO}_{2}$ film will also contain carbon which can interact with $\mathrm{SiO}_{2}$ as

$$
\mathrm{C}+\mathrm{SiO}_{2}=\mathrm{CO}+\mathrm{SiO} .
$$

This process results in thinning of the $\mathrm{SiO}_{2}$ film. Furthermore, different impurities influence the viscosity of the $\mathrm{SiO}_{2}$ film.

The conditions of $\mathrm{SiO}_{2}$ film formation are often referred to as "passive" in opposite to "active" conditions when the reaction product is gas-phase $\mathrm{SiO}$ which cannot create a protective film. 

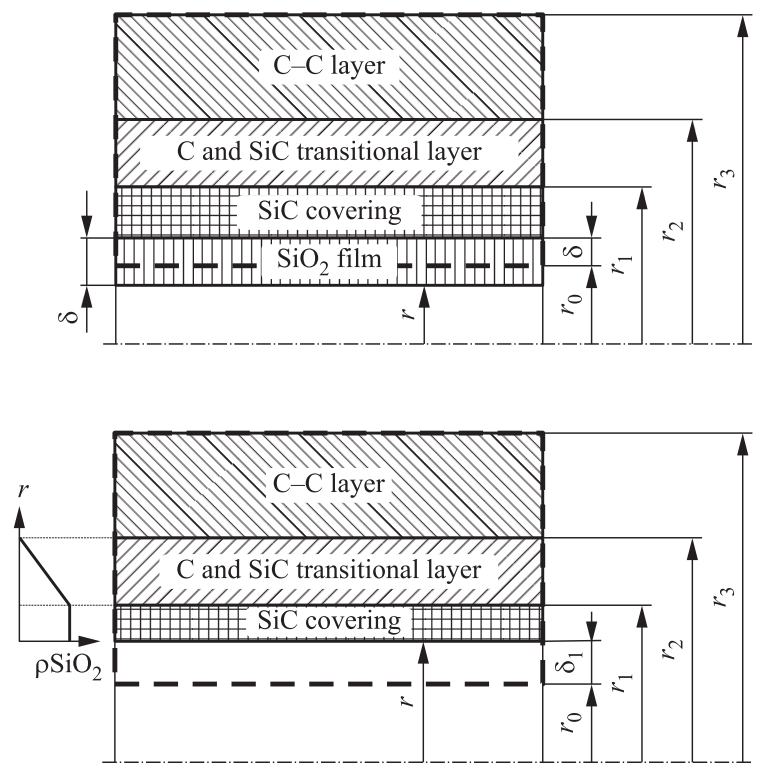

Figure 2 Schematic of carbide-ceramic CM destruction

The temperature of transition from active to passive conditions depends on the environment parameters such as pressure, concentration, and composition of oxidant components, as well as availability of carbon and other side components (including technical additives, determining the chemical bond energy between carbon and carbide during $\mathrm{SiC}$ covering formation) in the film. In some cases [1], the transition from active to passive conditions can be attributed to the temperature of $1967 \mathrm{~K}$. More detailed information can be found in [2].

In general, in $\mathrm{C}-\mathrm{SiC}$ system, the following physicochemical transformations with oxidants can take place both on the material surface and in the material itself. The film depletion process proceeds rapidly as soon as the transition temperature is reached. Its rate is determined by the $\mathrm{SiO}_{2}-\mathrm{SiC}$ reaction which produces gas-phase $\mathrm{SiO}$ and $\mathrm{CO}$ :

$$
\begin{gathered}
\text { solid } \\
\mathrm{SiC}+2 \mathrm{SiO}_{2}=3 \mathrm{SiO}+\mathrm{gas}
\end{gathered}
$$

Also, the film depletion rate is affected by mechanical destruction caused by the blowout of different gaseous products according to the reactions:

$$
\begin{array}{cccccc}
\text { solid } & \text { gas } & & \text { gas } & & \text { gas } \\
2 \mathrm{SiC}+ & 3 \mathrm{O}_{2} & = & 2 \mathrm{SiO} & + & 2 \mathrm{CO}_{2} \\
\mathrm{SiC}+2 \mathrm{CO}_{2} & = & \mathrm{SiO} & + & 3 \mathrm{CO} \\
\mathrm{SiC}+2 \mathrm{H}_{2} \mathrm{O} & = & \mathrm{SiO} & + & \mathrm{CO}+2 \mathrm{H}_{2}
\end{array}
$$


In "active" conditions, the covering ablation rate increases significantly as compared to "passive" conditions (refer to data in [1]).

It is worth noting that an important specific feature of this physical and thermophysical process is the existence of $\mathrm{SiO}_{2}$ barrier film. Its formation, motion, vaporization, and interaction with other substances determine and in some cases limit the rates of other physicochemical transformations. Thus, the results of classical thermochemical experiments, although can provide some necessary data on the kinetics of individual processes, do not allow getting insight into material and protective film behavior in real LRE conditions. Dynamics of film and covering formation, moving, and destruction can be studied only at conditions which reproduce all specific features of the flow in real nozzles.

\section{EXPERIMENTAL INVESTIGATION}

Model extensions made of carbon-carbon material with SiC covering (Nos. 1 and 2) were tested on oxygen-hydrogen LRE (Fig. 3) to examine the specific features of the processes discussed above. The tests were performed in a vacuum chamber with diffuser. Main characteristics of extensions and test conditions are presented in Table 1.

During the tests, the temperature of extension surface was $1700 \mathrm{~K}$, gas flow pressure was $30-33 \mathrm{kPa}$, and pressure in vacuum chamber was about $7.1 \mathrm{kPa}$ (see Table 1). One could expect that $\mathrm{SiC}$ oxidation takes place in passive conditions when oxidants (in this case, water vapor, mainly) reacts with $\mathrm{SiC}$ creating $\mathrm{SiO}_{2}$ layer (solid in given conditions).

The film growth rate is governed by the parabolic law $d \delta_{2} / d t=k / \delta_{2}$; consequently, $\delta_{2}=\sqrt{2 k t}+c$.

If the $\mathrm{SiO}_{2}$ layer is initially absent, the integration constant $c=0$ (for a combined layer, this constant will be equal to the $\mathrm{Al}_{2} \mathrm{O}_{3}$ layer thickness). The thickness of the reacted $\mathrm{SiC}$ layer $\left(\delta_{1}\right)$ can be then determined as

$$
\delta_{1}=\delta_{2} \frac{\mu_{\mathrm{SiC}}}{\mu_{\mathrm{SiO}_{2}}} \frac{\rho_{\mathrm{SiO}_{2}}}{\rho_{\mathrm{SiC}}}
$$

using the reaction stoichiometry.

These equations and the equations of thermal conductivity for the extension and vacuum chamber were solved together with the boundary layer equations accounting for the thermal film in the extension created by the LRE cooling jacket (solution procedure is presented in [3]).

Consider the results of experiments and numerical analysis. All the extensions tested had different ablations of material after the tests but kept their integrity. 

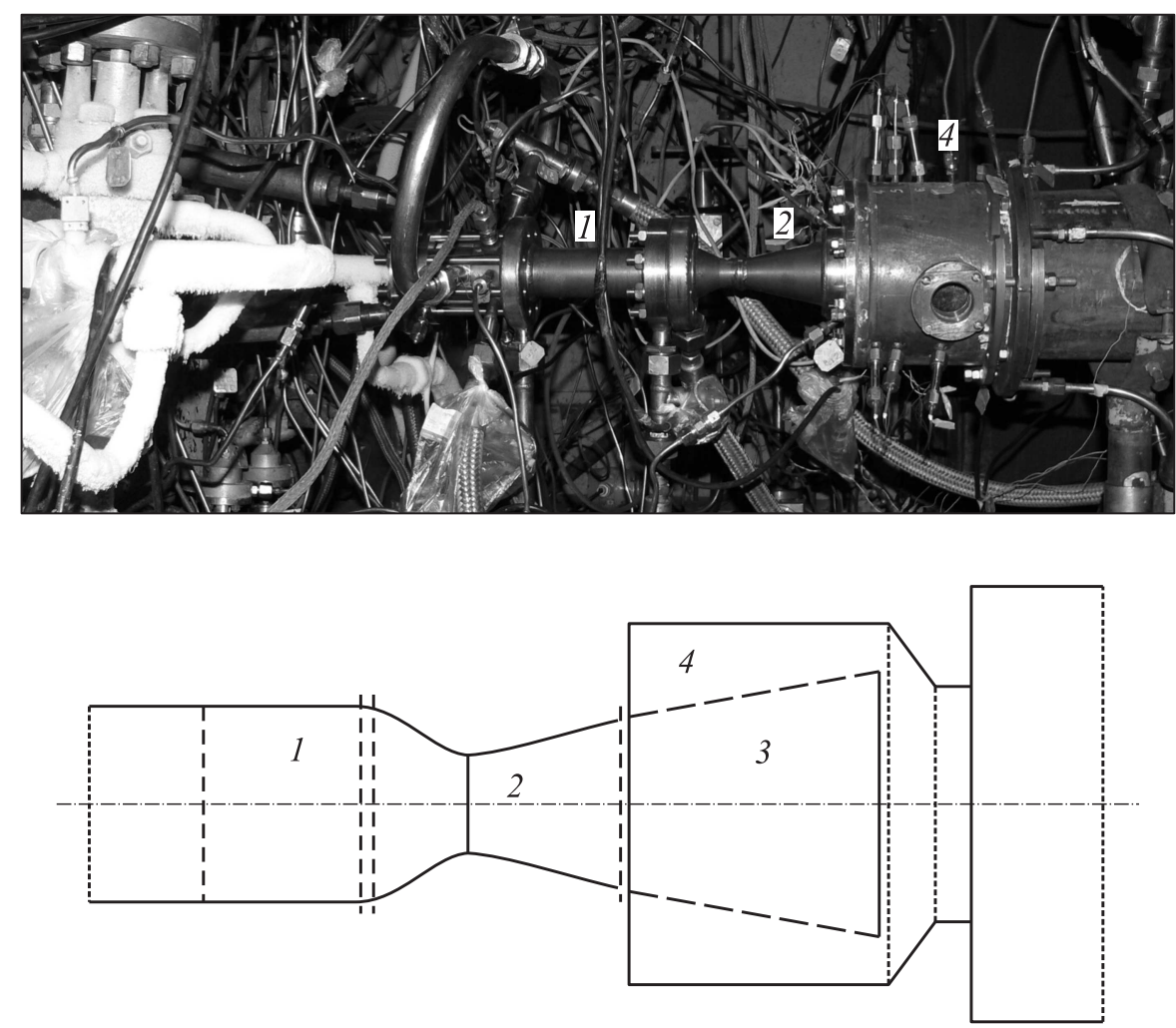

Figure 3 Model LRE with vacuum chamber and diffuser: 1 - model engine; $2-$ cooled nozzle; 3 - uncooled extension; and 4 - vacuum chamber

Table 1 Main characteristics of extension and test conditions

\begin{tabular}{ccrrrrc}
\hline \multirow{2}{*}{ Extension } & $\begin{array}{c}P_{c}, \\
\mathrm{MPa}\end{array}$ & $\begin{array}{c}P_{\mathrm{vc}}, \\
\mathrm{kPa}\end{array}$ & $\begin{array}{c}P_{\mathrm{ce}}, \\
\mathrm{kPa}\end{array}$ & $\begin{array}{c}T_{\max }, \\
\mathrm{K}\end{array}$ & $k_{m}$ & $\begin{array}{c}\text { Time, } \\
\mathrm{s}\end{array}$ \\
\hline No.1 C/C + SiC covering $+\mathrm{Al}_{2} \mathrm{O}_{3}$ & 9.06 & 7.1 & 32.6 & 1640 & 7.4 & 205 \\
No.2 C/C $+\mathrm{SiC}$ covering $+\mathrm{Al}_{2} \mathrm{O}_{3}$ & 8.3 & 10.4 & 30.4 & 1600 & 8.5 & 205 \\
\hline
\end{tabular}

Remark: $P_{c}-$ pressure in combustion chamber; $P_{\mathrm{vc}}-$ pressure in vacuum chamber; $P_{\mathrm{ce}}$ - gas flow pressure in the interface between cooled nozzle and extension; $T_{\max }-$ extension maximum temperature; and $k_{m}$ - component ratio. 

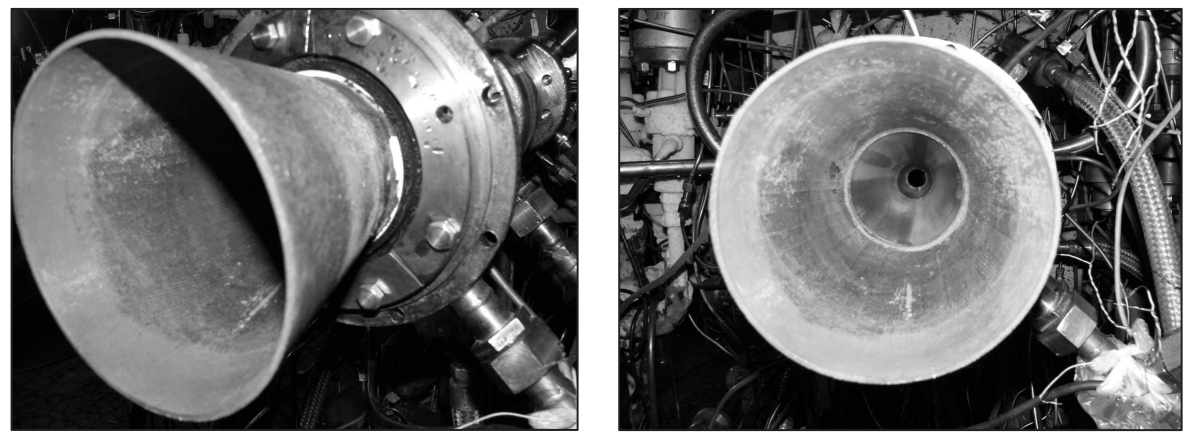

Figure 4 Extension No. 1 after testing

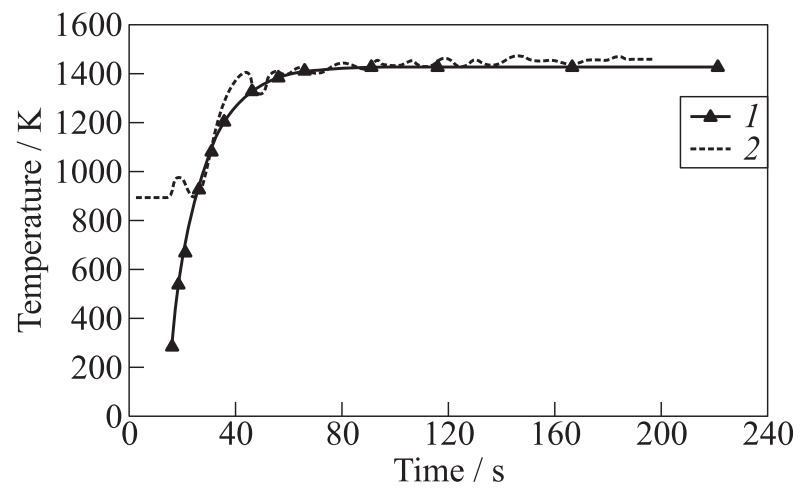

Figure 5 Calculated (1) and measured (2) temperature histories of the extension outer surface

For example, Fig. 4 shows extension No. 1 after the test. Considerable amounts of $\mathrm{SiO}_{2}$ were found during chemical analysis of the surface layer.

Figure 5 shows the time histories of the calculated extension temperature and that measured by infrared (IR) camera. Clearly, in the area of vacuum-chamber window, the temperature was near $1430 \mathrm{~K}$. Infrared camera measurements agree well with the calculated temperatures. Based on the measurements and calculations, the maximal temperature of the extension inner surface was found to be $1600 \mathrm{~K}$ (Fig. 6).

The calculated ablation value is shown in Fig. 7 by the lower curve. It is determined by two processes: by $\mathrm{SiO}_{2}$ film growth and interaction between $\mathrm{SiC}$ and $\mathrm{Al}_{2} \mathrm{O}_{3}$ when temperature reaches $1473 \mathrm{~K}$ [4]. This estimation was made assuming that the whole $\mathrm{Al}_{2} \mathrm{O}_{3}$ layer reacted with $\mathrm{SiC}$ evolving gas-phase 


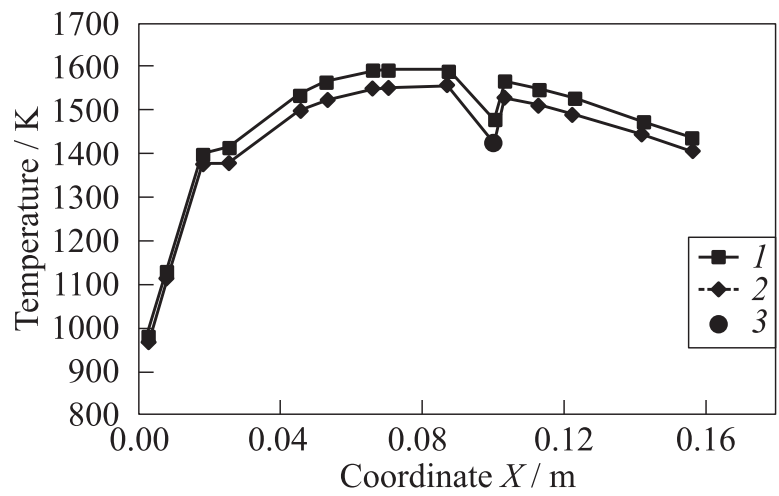

Figure 6 Temperature measured along the extension at the end of engine operation. Inner and outer surfaces: $1-\mathrm{Tw} 1 ; 2-\mathrm{Tw} 2$; and $3-\mathrm{IR}$

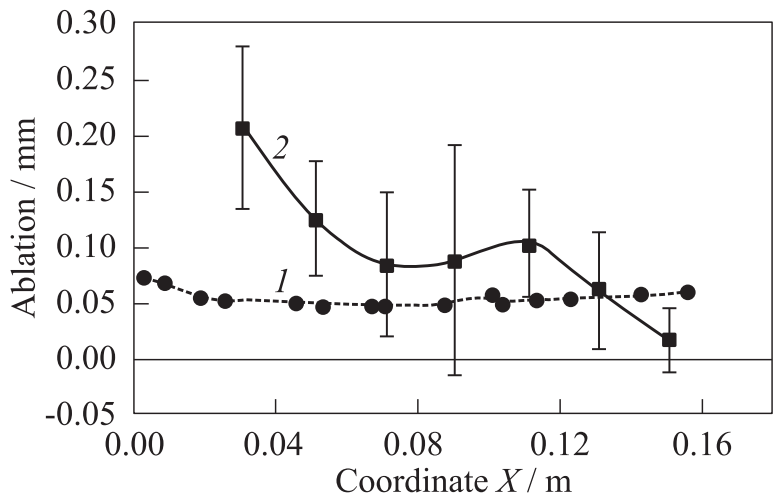

Figure 7 Calculated (1) and measured (2) linear ablation on the extesion surface

products. The results of linear ablation metering agree with the estimations in the area free of heat transfer intensification $(x>0.06 \mathrm{~m})$.

\section{CONCLUDING REMARKS}

Thus, the protective covering was shown to remarkably decrease the extension material ablation (by a factor of 3-5) and survived till the end of engine operation. Theoretically, it is better to use $\mathrm{SiO}_{2}$ instead of $\mathrm{Al}_{2} \mathrm{O}_{3}$, as it creates a diffusion barrier and does not exhibit additional interactions at the temperature range of interest. 


\section{REFERENCES}

1. Williams, S. D., D. M. Curry, D. C. Chao, and V. T. Pham. 1994. Ablation analysis of the Shuttle Orbiter oxidation protected reinforced carbon-carbon. 6th AIAA/ASME Joint Thermophysics and Heat Transfer Conference. Colorado Springs.

2. Rosner, D. E., and H. D. Allendorf. 1970. High-temperature kinetics of the oxidation and nitridation of pyrolytic silicon carbide in dissociated gases. J. Phys. Chem. 74(9):1829-39.

3. Volkov, N. N., and L.I. Volkova. 1999. The efficiency of gas curtain application for increasing the resistance of composite material extensions. Rus. J. Avia-Space Machinery Technol. 3:43-49.

4. Kislyi, P. S., A. Kh. Bodyan, V.S. Kindesheva, and F. S. Garibyan. 1981. Hightemperature metal heaters. Kiev: Naukova Dumka Publ. 